\title{
3 Research Suare \\ Realizing the potential of metallic iron for environmental remediation: Flee or adapt?
}

Rui Hu

Hohai University

Huichen Yang

University of Göttingen

Viet Cao

Hung Vuong University of Ho Chi Minh City

Bernard Konadu Amoah

Hohai University

Arnaud Igor Ndé-Tchoupé

Hohai University

Willis Gwenzi

University of Zimbabwe

Hans Ruppert

University of Göttingen

Chicgoua Noubactep ( $\nabla$ cnoubac@gwdg.de)

University of Göttingen

\section{Research Article}

Keywords: Electrochemical dissolution kinetics, Groundwater remediation, Permeable reactive barrier, Water treatment, Zero-valent iron.

Posted Date: March 3rd, 2021

DOI: https://doi.org/10.21203/rs.3.rs-193098/v1

License: (c) (i) This work is licensed under a Creative Commons Attribution 4.0 International License.

Read Full License 


\section{Abstract}

The evidence that metallic iron $\left(\mathrm{Fe}^{0}\right)$ is not an environmental reducing agent has been declared to be a claim. Researchers presenting their findings in a scientific journal have to accept the burden of proving that their argumentation has any validity. This 30 -year-lasting discussion within the $\mathrm{Fe}^{0}$ remediation community is alien to graduate chemists, as it is a century old electrochemistry knowledge. Nevertheless,

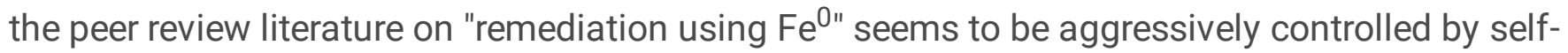
appointed experts (e.g., journal editors) who are not tolerating any alternative thinking. This communication demonstrates the fallacy of the view that $\mathrm{Fe}^{0}$ donates any electron to a dissolved species. The sole goal is to reconcile a proven efficient technology with his scientific roots, and enable the design of better $\mathrm{Fe}^{0}$ remediation systems.

\section{Metallic Iron For Environmental Remediation}

Twenty seven years ago, Matheson and Tratnyek [1] published highly counter-intuitive findings that metallic iron $\left(\mathrm{Fe}^{0}\right)$ could be oxidized by dissolved contaminants at circum-neutral $\mathrm{pH}$ values. Their results were reported to be confirmed two years later by Weber [2]. Since then, environmental scientists are mostly condidering $\mathrm{Fe}^{0}$ as a reducing agent for relevant aqueous species, including chlorinated organics $(\mathrm{RCl})$ [3]. Clearly, $\mathrm{RCl}$ reductive transformation is considered to be the cathodic half-reaction occurring simultanously with the anodic $\mathrm{Fe}^{0}$ oxidative dissolution (Eq. 1):

$\mathrm{Fe}^{0}+\mathrm{RCl}+\mathrm{H}^{+} \Rightarrow \mathrm{Fe}^{2+}+\mathrm{RH}+\mathrm{Cl}^{-}$

Any researcher familiar with the $\mathrm{Fe}^{0}$ remediation technology will confirm that this is the state-of-the-art knowledge $[4,5]$. Any reader, interested in following the path of the paradigm from Reynolds et al. [6] is encouraged to read Gillham [7]. In fact, Reynolds et al. [6] fortuitously found that trichloroethylene disappeared in $\mathrm{Fe}^{0}$-based vessels. This is virtually considered as the starting point for the $\mathrm{Fe}^{0}$ remediation technology which is now 30 years old and is widely recognized as a competent alternative for remediation of contaminated groundwater $[4,5,7]$ and the provision of safe drinking water [8-10]. Here, we contrast this misconception to the fundamental science of aqueous iron corrosion $\left(\mathrm{Fe}^{0} / \mathrm{H}_{2} \mathrm{O}\right.$ system).

\section{The Science Of The Fe/ho System}

In 1903, Willis Rodney Whitney established the science of the $\mathrm{Fe}^{0} / \mathrm{H}_{2} \mathrm{O}$ system which convincingly demonstrated that, at $\mathrm{pH}>4.5$ and under immersed conditions, only water can oxidize $\mathrm{Fe}^{0}$ in an electrochemical mechanism according to Eq. 2 [11]:

$\mathrm{Fe}^{0}+2 \mathrm{H}^{+} \Rightarrow \mathrm{Fe}^{2+}+\mathrm{H}_{2}(2)$ 
In particular, Whitney [11] demonstrated two important facts: (i) carbonic acid $\left(\mathrm{H}_{2} \mathrm{CO}_{3}\right)$ accelerates corrosion by supplementing protons $\left(\mathrm{H}^{+}\right)$in Eq. 2 or intensifying water dissociation, and (ii) dissolved oxygen $\left(\mathrm{O}_{2}\right)$ accelerates corrosion by consuming $\mathrm{Fe}^{2+}$ and favouring the forward reaction in Eq. 2 (i.e., Le Chatelier principle). In other words, all reports on aqueous iron corrosion by $\mathrm{O}_{2}$ are faulty. In terms of chemistry, $\mathrm{H}_{2} \mathrm{CO}_{3}$ and $\mathrm{O}_{2}$ enhance iron corrosion by an indirect mechanism or thanks to the Le Chatelier principle. This is basic knowledge to a chemist even to an undergraduate level. It then follows that $\mathrm{O}_{2}$ reduction is given by Eq. 3 [12]:

$4 \mathrm{Fe}^{2+}+\mathrm{O}_{2}+2 \mathrm{H}^{+} \Rightarrow 4 \mathrm{Fe}^{3+}+2 \mathrm{OH}^{-}(3)$

Similarly, the chemical reduction of $\mathrm{RCl}$ by Fell species can be written as in Eq. 4:

$2 \mathrm{Fe}^{2+}+\mathrm{RCl}+\mathrm{H}^{+} \Rightarrow 2 \mathrm{Fe}^{3+}+\mathrm{RH}+\mathrm{Cl}^{-}(4)$

To this point, the presentation demonstrates that the view that, under environmental conditions $(\mathrm{pH}>4.5)$, $\mathrm{RCl}$ reductive transformation in the presence of $\mathrm{Fe}^{0}$ is an electrochemical reaction is contrary to basic chemistry textbook knowledge. Thus, the $\mathrm{Fe}^{0}$ remediation literature has distorted the science of aqueous iron corrosion. In this regard, the $\mathrm{Fe}^{0}$ remediation research community has perpetuated and propagated the miskate for years now despite various efforts drawing attention to this error [13]. This mistake is attributed to insufficient literature review as the seminal paper by Whitney [11] was then 91 years old. Recent trends in journal editorial and review processes emphasizing the review and citation of recent literature has also contributed to the current scenario where researchers exclude 'old' knowledge, while simultaneously introducing conceptual errors. Clearly, researchers trying to restore the integrity of science now bear the burden of proof, and face resistance from experts (editors and reviewers) with questionable expertise. However, those researchers have basically no proofs to bring as they are just correcting an error which has been propagated over the years. The error has developed to an 'acceptable truth' by virtue of mere repeated citations, but it is common knowledge that repeating a lie does not make it the truth [14]. This communication considers that active researchers may also have the tendency to become attached to their ideas no matter how flawed they might be. Such a situation has made publishing on ' $\mathrm{Fe}{ }^{0}$ for water remediation' becoming an irrational discussion among scientists, rather than a rational competition among ideas underpinned by fundamental scientific knowledge $[15,16]$.

For contaminant removal in $\mathrm{Fe}^{0} / \mathrm{H}_{2} \mathrm{O}$ systems, there should be a recognizable and universal reality based on scientific principles. In this case, it is about the corrosion science of metallic iron in aqueous environments. To reach this reality, "good explanations should rise out of the ashes of those shown to be false" [16]. Accordingly, scientists seeking to reach the "recognizable and universal reality" on the fate of contaminants in $\mathrm{Fe}^{0} / \mathrm{H}_{2} \mathrm{O}$ systems should strive to entertain the two theories given above as concurrent hypotheses and find out which one enables a better explanation of their experimental results. This is currently not the case as even 'critical' reviews are written without any hint on controversy existing in the literature $[5,17]$. This communication is not addressing the related controversies, interested readers are 
referred to the following three representative articles: Gheju and Balcu [18], Ghauch [19], and Noubactep [17].

\section{The Future Of Fe-based Filtration Systems}

The view that $\mathrm{Fe}^{0}$ is a reducing agent for contaminant reduction under environmental conditions is faulty as demonstrated in Sect. 1. The main problem of $\mathrm{Fe}^{0}$ filters is the time-dependent decrease of it permeability $[20,21]$. There are many contributing factors to permeability loss, but the most important is the volumetric expansive nature of iron corrosion. Volumetric expansion implies that each oxide is at least twice larger in volume than the parent metal $\left(V_{\text {oxide }}>2 V_{\text {iron }}\right)$. The question arises how much oxide is generated in a $\mathrm{Fe}^{0}$ filter per unit time? Answering this question requires that the corrosion rate of used $\mathrm{Fe}^{0}$ specimens is known. However, this is not the case, and too little efforts have been directed at characterizing the reactivity of $\mathrm{Fe}^{0}$ materials $[22,23]$. This is very unfortunate in a context where it is welldocumented that the $\mathrm{Fe}^{0}$ corrosion rate can vary over several orders of magnitude [24].

Equations 1 and 4 demonstrate that twice more $\mathrm{Fe}^{0}$ is consumed for the reduction of $\mathrm{RCl}$ than it would have been in a electrochemical reaction (Eq. 1). Given the low solubility of $\mathrm{Fe}^{\mathrm{II}}$ and $\mathrm{Fe} \mathrm{Fll}^{\mathrm{III}}$ in water at $\mathrm{pH}>$ 4.5, this implies at least twice more oxides to fill the pores and induced permeability loss as has been assumed until now. When finally considering that only protons $\left(\mathrm{H}^{+}\right)$oxidizes $\mathrm{Fe}^{0}$, it becomes clear that pore filling by iron corrosion products must be considered before any other operating factors (e.g., foreign precipitates, $\mathrm{H}_{2}$ generation, suspended particles). In other words, despite three decades of intensive efforts to chracterize the long-term permeability of $\mathrm{Fe}^{0}$ filters, satisfactorily results are lacking because the system analysis underlying past efforts was not holistic. For instance, in the bulk of the studies, the $\mathrm{Fe}^{0}$ materials used is poorly or never characterized with respect to intrinsic reactivity (e.g. long-term corrosion rate). In other studies, high agitation rates that are not representative of operating conditions of $\mathrm{Fe}^{0}$ remediation systems are used $[18,19]$. Thus, systematic comparison of results among studies is problematic.

It may be surprizing to read that investigating the contribution of expansive iron corrosion to the process of permeability loss in $\mathrm{Fe}^{0}$ PRBs is an innovation. This becomes obvious, however, when it is recognized that no single contaminant can oxidize $\mathrm{Fe}^{0}$, while current models for predicting the operation of $\mathrm{Fe}^{0} \mathrm{PRBs}$ are mostly based on the stoichiometry of an electrochemical reaction between $\mathrm{Fe}^{0}$ and the contaminants of concern $[25,26]$. Thus, such models are premised on the wrong scientific principle. For more than a decade, admixing sand and non expansive aggregates with $\mathrm{Fe}^{0}$ was considered as "material dilution" with possible negative impacts on the decontamination process [27]. Only around 2010, it was proven that only hybrid systems (e.g., $\mathrm{Fe}^{0}$ /sand) can be sustainable, making "material dilution" rather a prerequisite for sustainability [28]. In other words, $\mathrm{Fe}^{0}$ filtration systems are yet to be properly considered as a special case of "electrochemical dissolution of metals in porous media". In such porous systems, the corrosion rate also depends on the pore size distribution [29]. 
The last important feature to be considered for the next generation $\mathrm{Fe}^{0} \mathrm{PRBs}$ is the validity of the design prerequisite that PRBs must have a higher hydraulic conductivity than the sorrounding aquifer $[7,21]$. It is certain that the hydraulic conductivity of any $\mathrm{Fe}^{0}$ PRB will decrease with time [28]. What will happen when the wall and the sorrounding porous environment have the same permeability? To the best of the author's knowledge, this issue has never been addressed in the $\mathrm{Fe}^{0}$ remediation literature.

The credibility of $\mathrm{Fe}^{0}$-based remediation system as a technology depends essentially on the quality of the work that researchers produce. The fact that a distortion of Corrosion Science has been prevailing in the $\mathrm{Fe}^{0}$ literature for three decades must be a concern to the whole scientific community. During the last decade, the situation has worsen to the extent that journal editors and grant referees reject manuscripts or proposals questioning the current paradigm with the summary comment "not relevant" or "lack of novelty". For manuscripts, the authors can migrate from journals to journals until they found more understanding and open-minded editors. For grant proposals however, there is almost no chance, because the 'best experts' are the same people who introduced the named mistakes. In a context of harsh competition for grant money, a single negative referee is mostly enough for rejection. This is a fundamental problem which cannot be resolved by a few individuals [30]. By making the problem better known to the public, the authors hope to contribute to its solution. It is also our proposal that journal editorial boards and reviewers avoid further acceptance of manuscripts further perpertuating or propagating the fundamental mistake highlighted here. This approach could redeem the $\mathrm{Fe}^{0}$ remediation technology from its current conceptual errors. That is the motivation for writing this short communication.

\section{Concluding Remarks}

This communication recalls that under environmental conditions the following occurs: (i) $\mathrm{Fe}^{0}$ is oxidized by water and by water alone, (ii) $\mathrm{Fe}^{2+}, \mathrm{H}_{2}$ and other species like green rust or $\mathrm{Fe}_{3} \mathrm{O}_{4}$ reduce contaminants (and $\mathrm{O}_{2}$ ), (iii) twice more $\mathrm{Fe}^{0}$ is needed to produce the number of electrons for the reduction by $\mathrm{Fe}^{2+}$, compared to the case where $\mathrm{Fe}^{0}$ would have been the reducing agent, and (iv) because of the very low solubility of $\mathrm{Fe}^{\mathrm{Il}}$ and $\mathrm{Fe}$ III species, iron oxides and hydroxides cannot migrate far from the $\mathrm{Fe}^{0}$ surface.

Iron oxides are larger in volume than $\mathrm{Fe}^{0}$ and will progressively fill the pores. For these reasons, expansive iron corrosion should be considered first when discussing the process of permeability loss. This has not been the case for the past three decades.

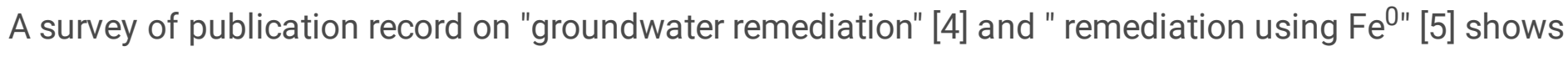
increasing publication numbers. This confirms the importance of the subject of study and its relevance to industrial technology, justifying a high level of research activities worldwide. This impressive publication record should have made any member of the community pride in this robust state of affairs [30]. However, the evidence that the large majority of these publications are propagating a mistake and that a circular reasoning is installed in the community is very disappointing. The present communication is a 
call for the $\mathrm{Fe}^{0}$ remediation research community to acknowledge its past mistakes, and embark a new path anchored on well-established scientific principles (i.e., aqueous corrosion of $\mathrm{Fe}^{0}$ ).

\section{Declarations}

Acknowledgements: This work was supported by the Ministry of Science and Technology of China through the Program "Driving process and mechanism of three dimensional spatial distribution of high risk organic pollutants in multi field coupled sites" (Project Code: 2019YFC1804303) and "Research on Mechanism of Groundwater Exploitation and Seawater Intrusion in Coastal Areas" (Project Code: 20165037412), and the program "Postgraduate Research \& Practice Innovation Program of Jiangsu Province" (Project Code: SJKY19_0519, 2019B60214). We acknowledge support by the German Research Foundation and the Open Access Publication Funds of the Göttingen University.

Author contribution: H.Y., V.C., B.K.A. and A.I.N.T conceived the presented idea and developed the theory and presented the initial draft. R.H., W.G., H.R. and C.N. supervised this work. W.G. supervised the redaction of the first draft and proof read the final manuscript. All authors contributed to the final manuscript.

Funding: Open Access funding enabled and organized by Projekt DEAL.

Competing interests: The authors declare no competing interests.

\section{References}

1. Matheson, L. J. \& Tratnyek, P. G. Reductive dehalogenation of chlorinated methanes by iron metal. Environ. Sci. Technol. 28, 2045-2053 (1994). )

2. Weber, E. J. Iron-mediated reductive transformations: investigation of reaction mechanism. Environ. Sci. Technol. 30, 716-719 (1996). )

3. O'Hannesin, S. F. \& Gillham, R. W. Long-term performance of an in situ "iron wall" for remediation of VOCs. Ground Water. 36, 164-170 (1998). )

4. Chen, Q. et al. Past, present, and future of groundwater remediation research: A scientometric analysis. Int. J. Environ. Res. Public Health 16,3975( 2019).

5. Thakur, A. K., Vithanage, M., Das, D. B. \& Kumar, M. A review on design, material selection, mechanism, and modelling of permeable reactive barrier for community-scale groundwater treatment.Environ. Technol. \& Innov. 19,100917( 2020).

6. Reynolds, G. W., Hoff, J. T. \& Gillham, R. W. Sampling bias caused by materials used to monitor halocarbons in groundwater. Environ. Sci. Technol. 24, 135-142 (1990). )

7. Gillham, R. W. Development of the granular iron permeable reactive barrier technology (good science or good fortune). In "Advances in environmental geotechnics: proceedings of the International 
Symposium on Geoenvironmental Engineering in Hangzhou, China, September 8-10, 2007"; Y. Chen, X. Tang, L. Zhan (Eds); Springer Berlin/London, pp. 5-15 (2008).

8. Giles, D. E., Mohapatra, M., Issa, T. B., Anand, S. \& Singh, P. Iron and aluminium based adsorption strategies for removing arsenic from water. J. Environ. Manage. 92, 3011-3022 (2011). )

9. Neumann, A. et al. Arsenic removal with composite iron matrix filters in Bangladesh: A field and laboratory study. Environ. Sci. Technol. 47, 4544-4554 (2013). )

10. Huang, Z., Cao, V., Nya, E. L., Gwenzi, W. \& Noubactep, C. Kanchan arsenic filters and the future of $\mathrm{Fe}^{0}$-based filtration systems for single household drinking water supply.Processes9,58( 2021).

11. Whitney, W. R. The corrosion of iron. J. Am. Chem. Soc. 25, 394-406 (1903). )

12. Stratmann, M. \& Müller, J. The mechanism of the oxygen reduction on rust-covered metal substrates. Corros. Sci. 36, 327-359 (1994).

13. Hu, R. et al. \& Noubactep, C.' Metallic iron for environmental remediation: Starting an overdue progress in knowledge.Water12,641(2020).

14. Noubactep, $\mathrm{C}$. The operating mode of $\mathrm{Fe} 0 / \mathrm{H} 2 \mathrm{O}$ systems: Hidden truth or repeated nonsense? Fresenius Environ. Bull. 28, 8328-8330 (2019). )

15. Chamberlin, T. C. The method of multiple working hypotheses.J. Geol. 5,837-848( 1897).

16. Fudge, D. S. Fifty years of J. R. Platt's strong inference.J. Exper. Biol. 217,1202-1204( 2014).

17. Noubactep, C. Metallic iron for environmental remediation: a review of reviews. Water Res. $\mathbf{8 5}, \mathbf{1 1 4}$ 123 (2015). )

18. Gheju, M. \& Balcu, I. Removal of chromium from $\mathrm{Cr}(\mathrm{VI})$ polluted wastewaters by reduction with scrap iron and subsequent precipitation of resulted cations. J. Hazard. Mater. 196, 131-138 (2011). )

19. Ghauch, A. Iron-based metallic systems: An excellent choice for sustainable water treatment. Freiberg Online Geosci. 32, 1-80 (2015). )

20. Antia, D. D. J. Water treatment and desalination using the eco-materials n- $\mathrm{Fe}^{0}(\mathrm{ZVI}), \mathrm{n}-\mathrm{Fe}_{3} \mathrm{O}_{4}, \mathrm{n}-$ $\mathrm{Fe}_{\mathrm{x}} \mathrm{O}_{\mathrm{y}} \mathrm{H}_{\mathrm{z}}\left[\mathrm{mH}_{2} \mathrm{O}\right]$, and $\mathrm{n}-\mathrm{Fe}_{\mathrm{x}}[\text { Cation }]_{\mathrm{n}} \mathrm{O}_{\mathrm{y}} \mathrm{H}_{\mathrm{z}}[\text { Anion }]_{\mathrm{m}}\left[\mathrm{rH}_{2} \mathrm{O}\right]$. In Handbook of Nanomaterials and Nanocomposites for Energy and Environmental Applications, (ed. O.V. Kharissova et al.) (2020).

21. Henderson, A. D. \& Demond, A. H. Long-term performance of zero-valent iron permeable reactive barriers: a critical review. Environ. Eng. Sci. 30, 401-423 (2007).

22. Li, J., Dou, X., Qin, H., Sun, Y. \& Yin, D. \& Guan X. Characterization methods of zerovalent iron for water treatment and remediation. Water Res. 148,70-85(2019).

23. Lufingo, M., Ndé-Tchoupé, A. I., Hu, R., Njau, K. N. \& Noubactep, C.. A novel and facile method to characterize the suitability of metallic iron for water treatment. Water11,2465( 2019).

24. Melchers, R. E. \& Petersen, R. B. A reinterpretation of the Roman off NBS data for corrosion of steels in soils. Corros. Eng. Sci. Techn. 53, 131-140 (2018). )

25. Sarr, D. Zero-valent-iron permeable reactive barriers - how long will they last? Remediation 11, 1-18 (2001). 
26. Santisukkasaem, U. \& Das, D. B. A non-dimensional analysis of permeability loss in zero-valent iron permeable reactive barrier (PRB). Transp. Porous Media126,139-159(2019).

27. Bi, E., Devlin, J. F. \& Huang, B. Effects of mixing granular iron with sand on the kinetics of trichloroethylene reduction. Ground Water29,56-62( 2009).

28. Domga, R., Togue-Kamga, F., Noubactep, C. \& Tchatchueng, J. B. Discussing porosity loss of Fe packed water filters at ground level.Chem. Eng. J. 263,127-134( 2015).

29. Stefanoni, M., Angst, U. M. \& Elsener, B. Kinetics of electrochemical dissolution of metals in porous media. Nat. Mater. 18, 942-947 (2019). )

30. Tien, C.. Remarks on adsorption manuscripts revised and declined: An editorial.Sep. Purif. Technol. $54,277-278(2007)$. 